\title{
Facilitating connections and supporting a learning community: together
}

\author{
Samantha Aston \\ University of Manchester \\ Michael Stevenson \\ University of Manchester \\ Padma Inala \\ University of Manchester
}

Keywords: community learning; online community; learning online; Pomodoro technique; Covid-19

\section{The challenge}

Faced with the comprehensive move to learning online, The University of Manchester Library's Teaching and Learning team took some time to reflect on existing online support and define an approach to what, and how, we would provide new learning opportunities for our students. The team worked with colleagues across the library and university to develop a fully online approach based on good practice by drawing upon our previous experience. This included a host of online resources, an existing online learning student-base through the University of Manchester Worldwide, and a previously developed open, online course to help students develop the skills for online learning.

The philosophy underpinning our approach to teaching design over the past year was inspired by Jesse Stommel's thoughts about asynchronous teaching:

We have to build for asynchronous, design real points of entry for students who can't be physically present at a particular time or in specific ways. This can (and should) intersect with more traditional synchronous face-to-face approaches [. . . ] [At] this moment, we should start by designing for the least privileged, most marginalised students, the ones with the least access (Stommel, 2020). 
We embodied this approach by creating new asynchronous materials to provide equitable provision for all students. We remained mindful of students' lack of connection, sense of community and peer support, which the library's My Learning Essentials (MLE) face-toface workshops typically fostered (Blake and Illingworth, 2015).

Anecdotally we were hearing that students were missing informally connecting with their peers - those serendipitous interactions and connections in a physical space that build a sense of community and belonging, such as before and after lectures and tutorials, or in MLE workshops. The 'academic and assessment' aspects of collaborative learning were rightly prioritised via our asynchronous offer; however, we recognised the need to support the 'social and psychological' aspects of learning as well (Laal and Ghodsi, 2012). We began to ask ourselves how we could create spaces for students to do this virtually, and synchronously, while demonstrating our care for a community that we would normally be so close to, when we felt so far away (Bali, 2020).

\section{The response}

Approaching this challenge, we acknowledged that the pedagogy used in an in-person setting would not translate directly to online settings, but we could still apply MLE's core principles: skills-focused, collaborative, open to all, and making best use of the technology available. Rather than converting all of our on-campus workshops into webinars, we wanted to ensure that the space we created was welcoming, connected learners with one another and the Library team, and had a focus on community.

Our solution was a 'Study Together' series. An online time and space for students to come together and work on academic tasks - including reading, writing, finding information and revising - that would reach across disciplines and programmes. It was intended to bring students together, add structure to their schedules, and provide dedicated time to focus on their individual academic work alongside their peers. We could not replicate our usual warm welcome, with tea, coffee and biscuits, but we could provide friendly faces and the opportunity to connect with others at spaced out intervals. We purposefully did not call 
them workshops when deciding on how we might be able to create a sense of community by bringing students together.

Our sessions were Writing Together, Searching Together and Revising Together (with Reading Together in development). Each Together session runs for 2 hours, and the design is grounded in the Shut Up and Write model used with our researchers in which we have successfully made use of the Pomodoro technique (Kneen et al., 2020). We experimented by using some new elements not previously used for MLE sessions. We made greater use of pre- and post-session blog posts and surveys to help students understand what to expect and to set their agendas. The Student Team also contributed to sessions by sharing their lived experience, knowledge and advice.

The Together series was partly successful. 174 students attended across 33 sessions. From feedback we know that it provided much needed interaction between students and gave many of them motivation to apply themselves to study, often delivering tangible outcomes from their time with us. Feedback on the sessions suggested that studying with other learners at a specified time, with facilitators on hand, helped many students to avoid feelings of procrastination and/or demotivation. For example:

This has been an extremely helpful session! I managed to do a lot more effective work and got all my questions answered. Thanks everyone! (Student, Searching Together)

Not all sessions were well attended, particularly Revising Together in semester 2. This could be due to factors such as timing and communication, and is being reviewed. Managing expectations proved tricky in Searching Together, with difficult questions from individuals conducting systematic reviews. Feedback from staff indicated less need for some of the Together series to have pre-session surveys, citing low engagement, possibly due to students being unsure of what they wanted or needed to know until they were in attendance. Allowing students the opportunity to share these thoughts at the start as well as throughout the session instead could also help encourage and increase 'on camera' and 'on mic' engagement. 


\section{Recommendations}

Our move to online teaching was careful and informed, but it happened more quickly than we would have liked or imagined. We are now considering how the Together series will fit into a future, post-COVID-19 offer. We will continue to create spaces where students can feel connected to each other and the support provided by the library and its people in order to nurture the university community going forward (hooks, 2003, p.130). Overarchingly, we have learnt that how we approach a challenge is as important as what we do to address that challenge. Our key learning points are:

1. Stopping to assess and scrutinise what is already in place in order to inform what can be done is crucial.

2. A robust philosophy sets the values and beliefs within the team, supporting the response to a problem.

3. Experimenting requires belief in that philosophy.

\section{References}

Bali, M. (2020) Pedagogy of care: COVID-19 edition. Available at: https://blog.mahabali.me/educational-technology-2/pedagogy-of-care-covid-19edition/ (Accessed: 7 June 2021).

Blake, J. and Illingworth, S. (2015) 'From the outside in: bringing student engagement to the centre', Widening Participation and Lifelong Learning, 17(2), pp.108-118. Available at: https://doi.org/10.5456/WPLL.17.2SI.107 (Accessed: 9 August 2021).

hooks, bell. (2003) Teaching Community: a pedagogy of hope. New York: Routledge.

Kneen, S., Opebiyi, F. and Theis, A. (2020) 'Shut up and pivot: moving writing support online', Northern Collaboration 2020 Virtual Conference. Durham University, Durham, UK 18-19 November. Available at: https://www.academiclibrariesnorth.ac.uk/northern-collaboration-2020 (Accessed: 7 June 2021). 
Laal, M. and Ghodsi, S.M. (2012) 'Benefits of collaborative learning', Procedia - Social and Behavioral Sciences, 31, pp.486-490. Available at: https://doi.org/10.1016/..sbspro.2011.12.091 (Accessed: 9 August 2021).

Stommel, J. [@Jessifer] (2020) A static recording of a synchronous Zoom conversation doesn't really count as "asynchronous” learning... [Twitter]. Available at: https://twitter.com/Jessifer/status/1263579433358761984 (Accessed: 7 June 2021).

\section{Author details}

Sam Aston SFHEA CeLP is a Learning Developer at The University of Manchester. Sam collaborates with staff and students to design and embed strategies for learning across the organisation to enable students to develop their academic practices.

Michael Stevenson is a Teaching and Learning Librarian at The University of Manchester. Michael teaches and supports students and researchers across a broad range of information literacy topics.

Padma Inala is a Teaching and Learning Librarian at The University of Manchester. Padma develops and delivers teaching to students and researchers to support their information literacy and academic skills. Her particular area of interest is in supporting online/distance learners. 